\title{
Rationalizing Indication of Ceramic Veneers: A Systematic Review
}

\author{
Rim Kallala ${ }^{1,4 *}$, Maryem Salhi Daly ${ }^{2}$, Yosra Gassara ${ }^{3,4}$, Rihab Dakhli ${ }^{3,4}$, Soumaya Touzi ${ }^{1,4}$, Dalenda Hadyaoui ${ }^{3,4}$, \\ Zohra Nouira ${ }^{3,4}$, Belhssen Harzallah ${ }^{3,4}$, Mounir Cherif ${ }^{3,4}$ \\ ${ }^{1}$ Department of Dental Anatomy at the dental faculty of Monastir, Tunisia \\ ${ }^{2}$ General Dental practitioner \\ ${ }^{3}$ Department of Fixed Prosthodontics in the Dentistry Clinic of Monastir, Tunisia \\ ${ }^{4}$ University of Monastir, Research laboratory of Occlusodontics and Ceramic Prostheses LR16ES15, 5000, Monastir, Tunisia
}

Article History
Received: 05.02 .2021
Accepted: 01.04 .2021
Published: 10.04 .2021
Journal homepage:
/Www.easpublisher.com

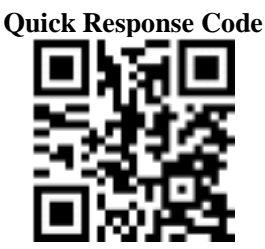

Abstract: Introduction: Ceramic veneers are an esthetic treatment which becomes a widespread approach satisfying increasing requirement of patients in terms of esthetics. It is a highly conservative approach treatment compared to total crowns as they require minimally preparation limited to enamel. The success of prosthetic rehabilitation with ceramic veneers depends on several parameters especially when patients are more demanding. That's why it is necessary to specify the indications and respect the limits of ceramic veneers. This systematic review aims to identify and update veneers Indications in order to ensure patient's satisfaction and offer long-lasting results. Material and method: A broad search of Pubmed, Cochrane Library, Ebscohost was conducted using all terms relevant to the subject. Relevant papers published in English and Frech were identified after a review of their titles, abstracts and full reading of papers. The search covered the period from January 2014 to January 2019. Results: A total of 909 articles were found: 18 are duplicated and 774 were excluded. 117 were selected according to the title and abstract. Finally, 69 articles were eligible for the present systematic review. Selected articles discuss veneers indications through 137 clinical reports : A total of 94 female, 38 male and 5 not identified patients. 6 patients were under to 18 years, 95 were more than 18 years and 36were not indicated. Conclusion: Ceramic veneers are indicated mainly to perform and correct shape and color. Several parameters should be taken on consideration. Some factors straight away contraindicated this type of restoration as insufficient enamel, pulpless teeth, poor oral hygiene.

Keywords: Veneers, Ceramic, Esthetic, Indications, Success.

Copyright (C) 2021 The Author(s): This is an open-access article distributed under the terms of the Creative Commons Attribution 4.0 International License (CC BY-NC 4.0) which permits unrestricted use, distribution, and reproduction in any medium for non-commercial use provided the original author and source are credited.

\section{INTRODUCTION}

Esthetic Dentistry has become a major focus for the public. Nowadays, with the accessibility of information's, patients are more demanding in terms of esthetics, especially for anterior teeth [1]. Porcelain laminate veneers have become a widespread approach which satisfies the increasing requirements. Moreover, due to the development of innovative ceramic materials, their clinical indications have been progressively increased [1-3].

That's why, it is necessary to specify indications and respect limits to ensure patients satisfaction with long-lasting results. Every clinical situation must be individualized and indication must be rationalized to achieve cited goals [1]. Very few researches and reviews target this subject in scientific literature.
Based on recent publications, this literature review aims to collect faithfully the highest number of successful clinical trials in order to extend and precise the situations where ceramic veneers should be the therapeutic approach. Precisely, the purpose is to rationalize indications.

\section{Materiel AND Method}

The literature review used on search strategy electronic databases: A broad search of Pubmed, Cochrane Library, Ebscohost was conducted. Full articles were retrieved and duplicates were eliminated by Mendeley software. Relevant papers published in English and French were identified after a review of their titles, abstracts and full reading of papers. The search covered the period from January 2014 to January 2019. A handsearch was also performed to develop the review. The following keywords relevant to the subject were used: ceramic-veneer-indication-limit-successfailure. Table 1 illustrates the research strategy for each 
Database. Two qualified reviewers carried out data extraction independently and disagreement was resolved by discussion.

\section{RESUlTS}

The database research produced 909 records: 18 were duplicates, 774 were eliminated after reading their titles and abstracts. Then, 48 articles were excluded after reading at the end, 69 articles fulfilling inclusion and eligibility criteria were selected for the literature review. The included articles contained: 1 literature review, 4 experimental study, 64 clinical report. The workflow of the paper screening process is reported in Figure 1:

\section{DISCUSSION}

In the last decade, Ceramic Veneers is considered a reliable restorative treatment, showing good longevity and low complication rates. Several systematic reviews reported follow-up periods ranging from 5 to 20 years, and survival rates ranging between $87 \%$ and $94 \%[1,4-6]$.

Layton et al. estimated cumulative survival rate for feldspathic veneers at 21-years [7].The present systematic review reported a total of 69 articles illustrated by 137 clinical cases from 18 countries (94 female, 38 male and 5 not mentioned). Their age average were over 18 years $(70 \%), 4 \%$ were under 18 and $26 \%$ were not mentioned.

Since 2009, Gil Tirlet and Jean Pierre Attal [8] included veneers in the therapeutic Gradient. Olivier Etienne [9], who modified Belser classification of

Ceramic Veneers (10), proposed 4 types:

Type I: correction of color

Type II: correction of form

Type III: abnormality of structure

Type IV: Correction of position

In the present this investigation, indications of Ceramic Veneers were collected, then, classified (table 2). Foundings were coherent with previous classification [9].

From this review, Ceramic Veneers are indicated mainly to correct the shape (type II) and color (type I). It seems to be the suitable treatment for both malposition, then Diastema closure, followed by discoloration. Our results are coherent with those of Zarone F et al. [1].

According to the review, Ceramic Veneers is a reliable restoration which allows form and shape improvement. These foundlings seems to be logical as the shape of anterior teeth is considered as substantial element in esthetic dentistry .Many studies demonstrated that Anterior diastema spoiled the smile attractiveness [77-79]. It is a common patient complaint, and has multifactorial etiology: dento maxillary disharmony, microdontia, persistence of the labial fernum attachment, agenesis [80].That's why the diastema cause should be identified and treated, sometimes, before the prosthetic rehabilitation. Several treatment options are available: orthodontic closure, Ceramic veneers or Resin Veneers [81-85]. According to Lynn [86], Porcelain Veneers are a clear requirement to close anterior diastemas offering dramatic improvement. Interproximal emergence profiles, biologic width, and papillary height must been taken on consideration to get excellent results. In the review, all diastemas were closed with a satisfactory outcome. The present study pointed out that both irregular size and atypical form are well managed with Ceramic Veneers. The peg-shaped lateral incisors is a frequent morphological variations of permanent teeth and laminated ceramic veneers appear to be a conservative treatment option for these situations, since in some cases, no tooth preparation is required [87]. Besides, Ceramic Veneers were indicated in 6 cases of lateral incisor agenesis, where canine were modified to replace missing tooth [58]. Neverless, the combination between ceramic veneers and other therapeutic attitudes could enable to obtain optimal esthetic success, as tooth proportions should be carefully considered: For example, it is established that proportion of the maxillary centrals is between $75 \%$ and $85 \%$ [88].

The orthodontic treatment allows space redistribution in the arch in order to come close to tooth golden proportion. As well as, gingivectomy which allows the tooth lengthening and both cervical margins and zenith harmonization [88]. For Such situations, a diagnostic wax-up, in conjunction with an intraoral mock-up, should be performed in order to visualize and simulate the final outcome [58]. A Digital Smile Design (DSD) could be useful to determine ideal tooth form and proportion according to the available space [20]. In the other hand, in recent years, the demand for having white and beautiful teeth is increasing, that's why management of discolored teeth has hight importance in esthetic dentistry [89]. Depending on the severity of discoloration, several treatment options are available: bleaching, micro abrasion, composite and porcelain veneers, porcelain crowns or sometimes a combination of them. Ceramic veneers are very efficient for discolored teeth with a long lasting result [30, 42, 52, 90]. According to Shadman N, a thickness of $0.8 \mathrm{~mm}$ is necessary to mask severe tooth discoloration [89]. Defective resin restorations were replaced in 9 cases by Ceramic Veneers and provided an adequate esthetic outcome. For those patients, discoloration of resin, requiring multiples times for reinterventions, was the chief complaint [37]. As well as Ceramic Veneers could be also a proper solution for tetracycline discoloration, especially when bleaching cannot remove dark staining satisfactorily [91]. In the other hand, 4 clinical cases of 
Fluorosis were managed with Ceramic Veneers .Only one article mentioned Fluorisis degree 4. According to Olivier Etienne, only degrees 3 and 4 require Ceramic Veneers [9]. Moreover, old ceramic and resin Veneers were replaced respectively 4 and 2 cases. For old resin veneers, marginal discoloration was the main chief complaint for the reintervention, that's why a bleaching was done after the removal of defective existing prosthesis .Here ceramic Veneers is the ideal treatment thanks to optic et mechanical qualities [92]. This restoration is helpful also for smile correction, harmonizing prosthetic treatment as it is minimally invasive. As well as, it can be useful in cases of deviation of inter-incisive middle and Persistence of lacteal tooth. It is also indicated for Gummy smile correction, requiring in some time, gingivotomy $[15,25,26,35,38,44,47,59,67,93]$.

To end, this study confirmed that ceramic Veneers are indicated especially to correct or perform shape and/or color, as it is mentioned by Olivier [9]. However, following situations were not included in the referring classification [9]: Abrasion/attrition, Erosion, Defective Ceramic /Resin Veneers, Lateral incisor agenesis and all indication in the field of Smile enhancement. The last entry is increasingly indicated especially for very expecting patients [20, 46]. Moreover, in the field of structure anomaly including Amelogenis Impectfreta, Tetracycline, Fluorios, patients are mainly requesting color improvement. For those reasons, the proposed classification (table3): classify indications according to patient chief compliant in order to provide maximum satisfaction. It could be considered more global and specific as it target directly patient's chief compliant.

All the indications above are reported faithfully in order to quantify and collect the maximum of indications performed by the dentists. This cannot replace in any way the importance of the clinical examination of the patient.

In the other side, some contraindication as, pupless teeth, poor oral hygiene, extensive restoration, insufficient enamel teeth were extrapolated from the review and should been taken on consideration when planning for esthetic rehabilitation with Ceramic Veneers.

Otherwise, 2 articles in the review [19, 93] classified bruxsim as a contre indication of Ceramic veneers. Mikeli [94] reported that it could pose a risk for all ceramic restorations. However, Melo [95, 96] didn't prove any association between previous entities. Others [97] recommended protecting Ceramic restorations by a mouth guard. That's why, it could be considered, currently, as a relative contraindication for Ceramic Veneers.

\section{CONCLUSION}

According to the present Review, Ceramic Veneers continue to grow as a major part of esthetic dentistry which is indicated especially to perform color and shape. They are reliable treatment option which could be an interesting alternative to single crowns that satisfies the increasing demands in terms of esthetics with long lasting results. Five panes should been taken on consideration to successes such restoration: a deep esthetic analysis, an appropriate indication, adequate clinical stages, fabrication and finally an adequate Bonding. Within the limitations of this systematic review, a proper indication could be considered a first key step to ensure. Successful rehabilitation with Ceramic Veneers. Further controlled clinical researches are necessary to more specifying.

Table-1: Search strategy for each database and relative results

\begin{tabular}{|l|l|}
\hline Pubmed & \multicolumn{1}{|c|}{ search strategy } \\
& 1\#: ("ceramics"[MeSH Terms] OR \\
& "ceramics"[All Fields]OR"ceramic"[All \\
& Fields]) AND "veneer" [All Fields] \\
& 1\# OR "indication"[MeSH Terms] \\
& 1\# OR "limit"[MeSH Terms] \\
& 1\# OR "failure"[MeSH Terms] \\
\hline Cochrane & 1\#: "ceramic"[ MeSH Terms] AND "veneer" \\
& [MeSHTerms] \\
& 1\#OR"indication"[MeSHTerms] \\
& 1\#OR"limit"[MeSHTerms] \\
& 1\#OR"success"[MeSHTerms] \\
& 1\# OR "failure"[MeSH Terms] \\
\hline Ebscohost & 1\#:"ceramic"AND"veneer" \\
& 1\#OR"indication" \\
& 1\#OR"limit" \\
& 1\#OR"success" \\
& 1\# OR "failure \\
\hline
\end{tabular}

Table-2: Indications of ceramic Veneers in included articles 
Rim Kallala et al; EAS J Dent Oral Med; Vol-3, Iss- 2 (Mar-Apr, 2021): 51-58

\begin{tabular}{|l|l|}
\hline Indications & Number of appearance in the articles \\
\hline Malposition $(11-37)$ & 28 \\
\hline Diastema(13,14,17,19-,22,29,30,31,33,38-49) & 27 \\
\hline Discoloration(9,12,21,23,30,31-35,37,42,44,50-54) & 18 \\
\hline Atypical Form(13,16,21,23,26,29,31,33,37,41,42,48-51,53,55,56) & 18 \\
\hline Irregular size $(18,21,25,28,29,34,35,37,40,41,47,49,52,55,57-59)$ & 17 \\
\hline $\begin{array}{l}\text { Fracture } \\
(16,21,23,33,34,37,44,49,54,60-63)\end{array}$ & 13 \\
\hline Defective resin Restoration(16,24,37,39,64,65,66,68,67) & 9 \\
\hline Smile Correction(8,18,21,27,35,47,59,68) & 8 \\
\hline Amelogenesis imperfect(15,16,21,49,69,70) & 6 \\
\hline Incisor agenesis(14,13,32,46,56,71) & 6 \\
\hline Fluorosis(19,30,49,72,73) & 5 \\
\hline Defective ceramic veneer(20,21,58,74) & 4 \\
\hline Erosion $(24,52,75,76)$ & 4 \\
\hline Gummy smile(35,38,58,67) & 4 \\
\hline Abrasion/attrition(23,52,76) & 4 \\
\hline Tetracyclines discoloration(40,45,124) & 3 \\
\hline Defective Resin veneer(14,68) & 2 \\
\hline Harmonizing a prosthesis(46) & 1 \\
\hline Deviation of inter-incisive middle(20) & 1 \\
\hline Persistenceof lacteal tooth(71) & 1 \\
\hline & \\
\hline
\end{tabular}

Table-3: Proposed Classification of Ceramic Veneers indications

\begin{tabular}{|c|c|c|c|}
\hline \multirow[t]{2}{*}{ Shape correction } & \multicolumn{2}{|c|}{ Color correction } & \multirow[t]{2}{*}{ Smile enhacement } \\
\hline & $\begin{array}{l}\text { Whithout Structure } \\
\text { anomaly }\end{array}$ & Structure anomaly & \\
\hline $\begin{array}{l}\text {-Anterior Diastema closure } \\
\text {-Atypical form } \\
\text {-Fracture } \\
\text {-Irregular size } \\
\text {-Slight Anomaly of position } \\
\text {-Lateral incisor agenesis (canine } \\
\text { reshaping) }\end{array}$ & $\begin{array}{l}\text {-discoloration } \\
\text {-Defective Resin } \\
\text { restoration }\end{array}$ & $\begin{array}{l}\text {-Amelogenis Impectfrcta } \\
\text {-Tetracycline coloration } \\
\text {-Fluorios } \\
\text {-Molar- Incisor } \\
\text { hypomineralization (MIH) - } \\
\text { Acquired enamel hypoplasia }\end{array}$ & $\begin{array}{l}\text {-harmonizing } \\
\text { prosthetic treatment } \\
\text {-Correction of } \\
\text { deviation of inter- } \\
\text { incisive middle } \\
\text {-Gummy smile }\end{array}$ \\
\hline $\begin{array}{l}\text {-Abrasion/attrition } \\
\text {-Erosion } \\
\text {-Defective old Veneers }\end{array}$ & & & \\
\hline
\end{tabular}

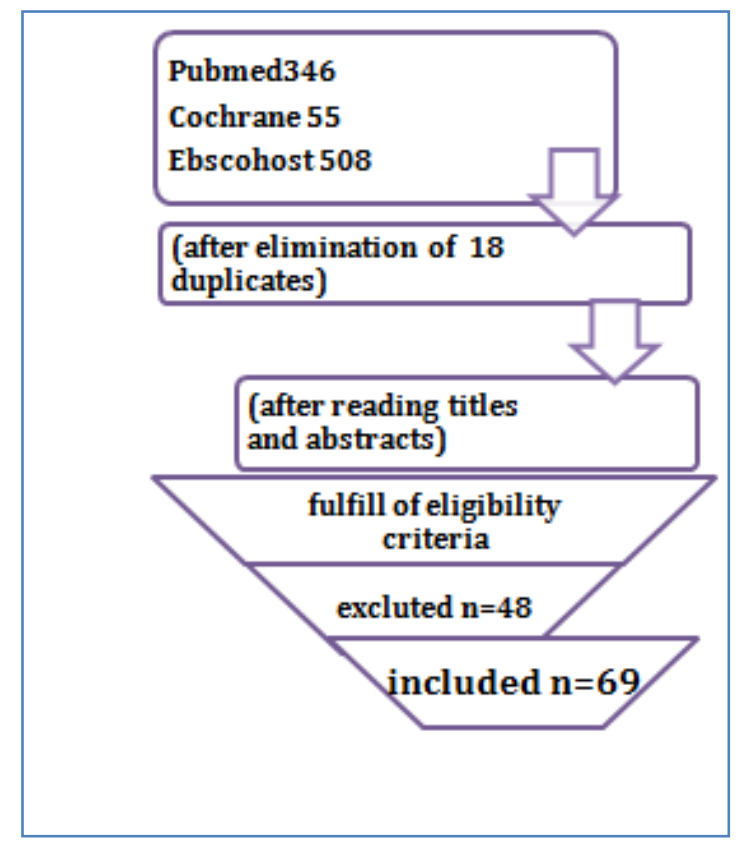

Fig-1: workfellow of the paper screening process

\section{REFERENCES}

1. ZARoNe, F., LeoNe, R., Di Mauro, M. I., Ferrari, M., \& SoRReNTiNo, R. (2018). No-preparation ceramic veneers: a systematic review. Journal of Osseointegration, 10(1), 17-22.

2. Zarone, F., Ferrari, M., Mangano, F. G., Leone, R., \& Sorrentino, R. (2016). "Digitally oriented materials": focus on lithium disilicate ceramics. International journal of dentistry, 2016.

3. Skyllouriotis, A. L., Yamamoto, H. L., \& Nathanson, D. (2017). Masking properties of ceramics for veneer restorations. The Journal of prosthetic dentistry, 118(4), 517-523.

4. Morimoto, S., Albanesi, R. B., Sesma, N., Agra, C. M., \& Braga, M. M. (2016). Main Clinical Outcomes of Feldspathic Porcelain and GlassCeramic Laminate Veneers: A Systematic Review and Meta-Analysis of Survival and Complication Rates. International

Prosthodontics, 29(1).

5. Beier, U. S., Kapferer, I., Burtscher, D., \& Dumfahrt, H. (2012). Clinical performance of 
porcelain laminate veneers for up to 20 years. International Journal of Prosthodontics, 25(1).

6. Petridis, H. P., Zekeridou, A., Malliari, M., Tortopidis, D., \& Koidis, P. (2012). Survival of ceramic veneers made of different materials after a minimum follow-up period of five years: a systematic review and meta-analysis. Eur $J$ Esthet Dent, 7(2), 138-152.

7. Layton, D. M., \& Walton, T. R. (2012). The up to 21-year clinical outcome and survival of feldspathic porcelain veneers: accounting for clustering. International Journal of Prosthodontics, 25(6).

8. Tirlet, G., \& Attal, J. P. (2009). Le gradient thérapeutique. Inf dent, 25(41/42), 2561-2568.

9. Etienne, O. (2013). Les facettes en céramique. Paris : $C d P, 5-21$.

10. Belser, U. C., Macne, P., \& Macne, M. (1997). Ceramic laminate veneers: continuous evolution of indications. Journal of Esthetic and Restorative Dentistry, 9(4), 197-207.

11. Kumar, G. V., Poduval, T. S., Reddy, B., \& Reddy, P. S. (2014). A study on provisional cements, cementation techniques, and their effects on bonding of porcelain laminate veneers. The Journal of Indian Prosthodontic Society, 14(1), 42-49.

12. Nakamura, M., \& Matsumura, H. (2014). The 24year clinical performance of porcelain laminate veneer restorations bonded with a two-liquid silane primer and a tri-n-butylborane-initiated adhesive resin. Journal of oral science, 56(3), 227-230.

13. Sulejmani, M., Sulejmani, F., Saiti, B., \& Ahmeti, B. (2016). Non-invasive ceramic veneers as an alternative to preserve tooth structure and crown lengthening via gingivoplasty in achieving aesthetics. Apolonia.

14. Bissasu, S. M., \& Al-Houri, N. A. (2014). Replacement of missing lateral incisors with lithium disilicate glass-ceramic veneer-fixed dental prostheses: a clinical report. Clinical case reports, 2(4), 128.

15. Büchi, D., Fehmer, V., Sailer, I., Wolleb, K., \& Jung, R. (2014). Minimally invasive rehabilitation of a patient with amelogenesis imperfecta. International Journal of Esthetic Dentistry, 9(2), 134-45.

16. Ozturk, E., \& Bolay, S. (2014). Survival of porcelain laminate veneers with different degrees of dentin exposure: 2-year clinical results. J Adhes Dent, 16(5), 481-9.

17. Decurcio, R. A., Cardoso, P. D. C., Rodrigues de Magalhães, A. P., \& Medeiros, E. (2015). A Harmonious Smile with Minimal Biological Costs. Journal of Cosmetic Dentistry, 31(2).

18. Piwowarczyk, A., Blum, J., \& Abendroth, H. (2015). Non-prep restoration of an ankylosed incisor: A case report. Quintessence International, 46(4).
19. Srivastava, V. K., \& Baranwal, A. (2015). Aesthetic management of anterior diastema using porcelain veneers: A Case Report. Clinical Dentistry (0974-3979), 9(7).

20. Guzmán-Armstrong, S., \& Maia, R. R. (2016). Conservative treatment planning in veneer replacement. The Journal of prosthetic dentistry, 115(4), 393-396.

21. Park, S., Ercus, M.S., Barquero, D., Figueira, J. (2016).

Masterfulmaneuverschallengesinminimallyinvasive caseswithallceramic materials. J Cosmet Dent, 32(1):28-53.

22. Watanabe, M. (2016). Minimally invasive veneer restoration with ceramic-based restorativematerial. Dent Economics; 7(3):78-110.

23. Karagözoğlu, İ., Toksavul, S., \& Toman, M. (2016). 3D quantification of clinical marginal and internal gap of porcelain laminate veneers with minimal and without tooth preparation and 2-year clinical evaluation. Quintessence International, 47(6).

24. Mahn, E. (2017). Two approaches, one goal: Digital expertise versus manual skill in the fabrication of ceramicveneers. Int Dent; 7(1):20-6.

25. Tsubota, K., \& Obara, S. (2017). Correcting Malaligned Teeth with the Biological Tissue Adaptation Technique. Journal of Cosmetic Dentistry, 33(2).

26. Tsubota, K. (2017). Ten-year clinical observation of a porcelain laminate veneer seated with biological tissue adaptation (BTA) technique. Journal of oral science, 59(2), 311-314.

27. Kuday, H., \& Kuday, N. Ö. (2017). MicroLayering Prepless Veneers. Journal of Cosmetic Dentistry, 32(4).

28. Stefano Patroni, D. M., \& Cocconi, R. (2017). From orthodontic treatment plan to ultrathin noprep CAD/CAM temporary veneers. Int J Esthet Dent, 12, 504-522.

29. Freedman, G. A. (2011). Contemporary Esthetic Dentistry-E-Book. Elsevier Health Sciences.

30. Jayalakshmi, N. L., Mathew, A. T., Kuruvila, A., \& Kakkadathu, S. (2017). Porcelain laminate veneers-A novel dimension to minimalism in prosthodontics: A case series. Journal of International Oral Health, 9(4), 183.

31. D'Arcangelo, C., Vadini, M., D'Amario, M., Chiavaroli, Z., \& De Angelis, F. (2018). Protocol for a new concept of no-prep ultrathin ceramic veneers. Journal of Esthetic and Restorative Dentistry, 30(3), 173-179.

32. Silva, G., Normandes, A. C., Barros Júnior, E., Gatti, J., Maranhão, K., Reis, A. C., ... \& Barros, T. (2018). Ceramic Laminate Veneers for Reestablishment of Esthetics in Case of Lateral Incisor Agenesis. Case reports in dentistry, 2018.

33. Tuzzolo Neto, H., Nascimento, W. F. D., Erly, L., Ribeiro, R. A., Barbosa, J. D. S., Zambrana, J. M., ... \& Costa, C. (2018). Laminated veneers with 
stratified feldspathic ceramics. Case reports in dentistry, 2018.

34. Liebermann, A., Edelhoff, D., Prandtner, O., \& Saeidi Pour, R. (2018). Minimally invasive treatment of an ankylosed, severely discolored, and intruded central incisor with a masking ceramic veneer: A clinical report. Int $J$ Periodontics Restorative Dent, 38, 121-126.

35. Souza, R. O. A., Barbosa, F. P., de Araújo, G. M., Miyashita, E., Bottino, M. A., de Melo, R. M., \& Zhang, Y. (2018). Ultra-thin monolithic zirconia veneers: reality or future? Report of a clinical case and one-year follow-up. Operative dentistry, 43(1), 3.

36. Ritter, A. V., Cunha, L. F., \& Correr, G. M. (2018). Esthetic and functional management of an ankylosed central incisor with a conservative restorative approach. Journal of Esthetic and Restorative Dentistry, 30(4), 269-274.

37. Rinke, S., Pabel, A. K., Schulz, X., Rödiger, M., Schmalz, G., \& Ziebolz, D. (2018). Retrospective evaluation of extended heat-pressed ceramic veneers after a mean observational period of 7 years. Journal of Esthetic and Restorative Dentistry, 30(4), 329-337.

38. Alencar, M.S., Araújo, D.F., MaenosonoRM,IshikiriamaBL, Francischone, C., Ishikiriama, S.K. (2014). Reestablishmentofestheticswithminimumthickness veneers:aoneyearfollowupcasereport.QuintessenceI $n t, 45(7): 593-7$.

39. da Cunha, L. F., Pedroche, L. O., Gonzaga, C. C., \& Furuse, A. Y. (2014). Esthetic, occlusal, and periodontal rehabilitation of anterior teeth with minimum thickness porcelain laminate veneers. The Journal of prosthetic dentistry, 112(6), 1315-1318.

40. Banerjee, S., Pal, S., \& Giri, T. K. (2014). Porcelain laminate veneers-a panacea for a decrepit smile. Clinical Dentistry (0974-3979), 8(2).

41. Selz, C. F., Jung, B. A., \& Guess, P. C. (2015). An interdisciplinary noninvasive all-ceramic treatment concept for nonsyndromic oligodontia in adolescence. Quintessence International, 46(2).

42. Zandinejad, A., Lin, W. S., Atarodi, M., AbdelAzim, T., Metz, M. J., \& Morton, D. (2015). Digital workflow for virtually designing and milling ceramic lithium disilicate veneers: a clinical report. Operative dentistry, 40(3), 241-246.

43. Miro, A. J., Shalman, A., Morales, R., \& Giannuzzi, N. J. (2015). Esthetic smile design: Limited orthodontic therapy to position teeth for minimally invasive veneer preparation. Dental Clinics, 59(3), 675-687.

44. Morita, R. K., Hayashida, M. F., Pupo, Y. M., Berger, G., Reggiani, R. D., \& Betiol, E. A. G. (2016). Minimally invasive laminate veneers: clinical aspects in treatment planning and cementation procedures. Case reports in dentistry, 2016.
45. Pimentel, W., Teixeira, M. L., Costa, P. P., Jorge, M. Z., \& Tiossi, R. (2016). Predictable outcomes with porcelain laminate veneers: a clinical report. Journal of Prosthodontics, 25(4), 335-340.

46. Berry, R., Jayna, A., \& Chaudhary, A. (2016). POST ORTHODONTIC ESTHETIC SMILE DESIGNING. Guident, 9(6).

47. da Cunha, L. F., de Almeida Kintopp, C., Baechtold, M. S., Correr, G. M., \& Gonzaga, C. C. (2017). Premium protocol for planning a periodontal-restorative approach: Conservative, predictable, and reproducible. Quintessence International, 48(7).

48. Fernandes da Cunha, L., Procopiak Gugelmin, B., Gaião, U., Castiglia Gonzaga, C., \& Correr, G. M. (2018). Tooth movement with elastic separators before ceramic veneer treatment: Rearranging asymmetric diastemas by managing the horizontal distance. Quintessence International, 49(2).

49. El-Mowafy, O., El-Aawar, N., \& El-Mowafy, N. (2018). Porcelain veneers: An update. Dental and medical problems, 55(2), 207-211.

50. da Cunha, L. F., Mukai, E., Hamerschmitt, R. M., \& Correr, G. M. (2015). Fabrication of lithium silicate ceramic veneers with a CAD/CAM approach: a clinical report of cleidocranial dysplasia. The Journal of prosthetic dentistry, 113(5), 355-359.

51. Calicchio, L., Kyrillos, M., Moreira, M., Silva, E., Giordani, G., Meloti, F., ... \& Silva10, J. (2016). A contemporary view on Dentistry. Accurate diagnosis guiding functional and aesthetic results. Journal of Clinical Dentistry \& Research, 13(1).

52. Durán Ojeda, G., Henríquez Gutiérrez, I., Guzmán Marusic, Á., Báez Rosales, A., \& Tisi Lanchares, J. P. (2017). A step-by-step conservative approach for CAD-CAM laminate veneers. Case reports in dentistry, 2017.

53. Martins, A. V., Albuquerque, R. C., Santos, T. R., Silveira, L. M., Silveira, R. R., Silva, G. C., \& Silva, N. R. (2017). Esthetic planning with a digital tool: A clinical report. The Journal of prosthetic dentistry, 118(6), 698-702.

54. Albino, L. G., Chaves, E. T., Lima, V. P., \& Lima, G. S. (2019). Restoration of a single darkened central incisor with a modified ceramic veneer. The Journal of prosthetic dentistry, 121(3), 369-372.

55. Savi, A., Crescini, A., Tinti, C., \& Manfredi, M. (2015). Ultra-Thin Veneers Without Tooth Preparation in Extensive Oligodontia. International Journal of Periodontics \& Restorative Dentistry, 35(6).

56. Jain, A., Ponnappa, K. C., Yadav, P., Rao, Y., Yadav, B. K., \& Gupta, P. (2015). An Esthetic Application of Lithium Disilicate Porcelain Veneer for Replacing a Missing Maxillary Central Incisor. Journal of International Oral Health, 7(10), 125. 
57. Ferreira, C. F., Oderich, E., Boff, L. L., \& Volpato, C. A. (2016). Step-by-Step Resin Bonding of Ceramic Veneers in the Anterior Maxilla: A Case Report. The Journal of the Tennessee Dental Association, 96(1), 47-52.

58. Trushkowsky, R., Arias, D. M., \& David, S. (2016). Digital Smile Design concept delineates the final potential result of crown lengthening and porcelain veneers to correct a gummy smile. Int $J$ Esthet Dent, 11(3), 338-54.

59. Hanson, M. (2017). Another look at 'dental economics. Dent Economics, 107:60-3

60. Clavijo, V., Bocabella, L., Schertel Cassiano, L., \& Duarte Jr, S. (2016). Reproducing Optical Properties of Anterior Teeth after UltraConservative Preparation. Journal of Esthetic and Restorative Dentistry, 28(5), 267-276.

61. Liddelow, G., \& Carmichael, G. (2016). The restoration of traumatized teeth. Australian dental journal, 61, 107-119.

62. Lin, W. S., Harris, B. T., Phasuk, K., Llop, D. R., \& Morton, D. (2018). Integrating a facial scan, virtual smile design, and $3 \mathrm{D}$ virtual patient for treatment with CAD-CAM ceramic veneers: A clinical report.The Journal of prosthetic dentistry, 119(2), 200-205.

63. Ceinos, R., Pouyssegur, V., Allard, Y., \& Bertrand, M. F. (2018). Esthetic rehabilitation of the smile with partial laminate veneers in an older adult. Clinical case reports, 6(8), 1407.

64. Censi, R., Vavassori, V., Borgonovo, A. E., \& Re, D. (2014). Esthetic rehabilitation of a severely compromised anterior area: combined periodontal and restorative approach. Case reports in dentistry, 2014.

65. Lin, W. S., Zandinejad, A., Metz, M. J., Harris, B. T., \& Morton, D. (2015). Predictable restorative work flow for computer-aided design/computeraided manufacture-fabricated ceramic veneers utilizing a virtual smile design principle. Operative dentistry, 40(4), 357-363.

66. Fernandes da Cunha, L., Castiglia Gonzaga, C., Saab, R., Mahammad Mushashe, A., \& Correr, G. M. (2015). Rehabilitation of the dominance of maxillary central incisors with refractory porcelain veneers requiring minimal tooth preparation. Quintessence International, 46(10).

67. Fragalli, L.G., Carlos, L., Júnior, O. (2015). Facets ceramic combining aesthetics and dental gingival. Eur J Orthod, 7:13-5.

68. Design, D.S. (2017). "Natural Veneers" using CAD milled monolithicceramicsandthe DSD (digitalsmiledesign)digitalworkflowincorporatingn aturaltoothlibraries. AustrDentPract, 3:44-151.

69. Saeidi Pour, R., Edelhoff, D., Prandtner, O., \& Liebermann, A. (2015). Rehabilitation of a patient with amelogenesis imperfecta using porcelain veneers and $\mathrm{CAD} / \mathrm{CAM}$ polymer restorations: A clinical report. Quintessence International, 46(10).
70. Shibata, S., Taguchi, C. M. C., Gondo, R., Stolf, S. C., \& Baratieri, L. N. (2016). Ceramic veneers and direct-composite cases of amelogenesis imperfecta rehabilitation. Operative dentistry, 41(3), 233-242.

71. Lameira, C. E. C. M., Mestrener, S. R., Pini, N. I. P., Salomão, F. M., Pesqueira, A. A., \& Fagundes, T. C. (2018). Conservative Approach for Treatment of Maxillary Lateral Incisor Agenesis With the Deciduous Tooth Retained: 18-Month FollowUp. Operative dentistry, 43(2), 121-127.

72. Slaska, B., Liebman, A. I., \& Kukleris, D. (2015). Restoration of fluorosis stained teeth: a case study. Dental Clinics, 59(3), 583-591.

73. El Mourad, A. M. (2018). Aesthetic rehabilitation of a severe dental fluorosis case with ceramic veneers: a step-by-step guide. Case reports in dentistry, 2018.

74. Faus-Matoses, V., Faus-Matoses, I., Ruiz-Bell, E., \& Faus-Llácer, V. J. (2017). Severe tetracycline dental discoloration: Restoration with conventional feldspathic ceramic veneers. A clinical report. Journal of clinical and experimental dentistry, 9(11), e1379.

75. Okida, R. C., Santos, D. M. D., Vechiato Filho, A. J., Andreotti, A. M., Medeiros, R. A. D., \& Goiato, M. C. (2014). Prosthetic rehabilitation of a patient with gastroesophageal reflux disease: 4-year followup. Case reports in dentistry, 2014.

76. Resende, T. H., Reis, K. R., Schlichting, L. H., \& Magne, P. (2018). Ultrathin CAD-CAM ceramic occlusal veneers and anterior bilaminar veneers for the treatment of moderate dental biocorrosion: A 1.5-year follow-up. Operative dentistry, 43(4), 337346.

77. Rosenstiel, S. F., \& Rashid, R. G. (2002). Public preferences for anterior tooth variations: a webbased study. Journal of Esthetic and Restorative Dentistry, 14(2), 97-106.

78. Fernandez, R., Eisa, E., Ashi, A., Farrash, H., \& Busaeed, A. Effect of diastema on smile perception in a saudi population.

79. How attractive is the Maxillary Midline Diastema?. (2020). Perception of Undergraduate Students Attending a Nigerian University, 5(1):4.

80. Jaija, A. M. Z., El-Beialy, A. R., \& Mostafa, Y. A. (2016). Revisiting the factors underlying maxillary midline diastema. Scientifica, 2016.

81. De Araujo Jr, E. M., Fortkamp, S., \& Baratieri, L. N. (2009). Closure of diastema and gingival recontouring using direct adhesive restorations: a case report. Journal of Esthetic and Restorative Dentistry, 21(4), 229-240.

82. Wolff, D., Kraus, T., Schach, C., Pritsch, M., Mente, J., Staehle, H. J., \& Ding, P. (2010). Recontouring teeth and closing diastemas with direct composite buildups: a clinical evaluation of survival and quality parameters. Journal of dentistry, 38(12), 1001-1009.

83. Chu, C. H., Zhang, C. F., \& Jin, L. J. (2011). Treating a maxillary midline diastema in adult 
patients: a general dentist's perspective. The Journal of the American Dental Association, 142(11), 1258-1264.

84. Baez Rosales, A., De Nordenflycht Carvacho, D., Schlieper Cacciutolo, R., Gajardo Guineo, M., \& Gandarillas Fuentes, C. (2015). Conservative approach for the esthetic management of multiple interdental spaces: a systematic approach. Journal of esthetic and restorative dentistry, 27(6), 344354.

85. Llerena-Icochea, A., Velo, M., Borges, A. F. S., Mondelli, R., \& Furuse, A. (2020). Multidisciplinary approach for anatomical correction and diastema closure with laminates veneers-a clinical report. Brazilian Dental Science, 23(2), 9-p.

86. Jones, L. A., \& Robinson, M. Y. (2002). A case study: sthetic \& biologic manengment of a diastema closure using porcelain bonded restorations for excellent \& predictable result.

87. Alberton, S. B., Alberton, V., \& de Carvalho, R. V. (2017). Providing a harmonious smile with laminate veneers for a patient with peg-shaped lateral incisors. Journal of conservative dentistry: JCD, 20(3), 210.

88. Álvarez-Álvarez, L., Orozco-Varo, A., ArroyoCruz, G., \& Jiménez-Castellanos, E. (2019). Width/length ratio in maxillary anterior teeth. Comparative study of esthetic preferences among professionals and laypersons. Journal of Prosthodontics, 28(4), 416-420.

89. Shadman, N., Kandi, S. G., Ebrahimi, S. F., \& Shoul, M. A. (2015). The minimum thickness of a multilayer porcelain restoration required for masking severe tooth discoloration. Dental research journal, 12(6), 562.

90. Chu, S. J., \& Mieleszko, A. J. (2014). Colormatching strategies for non-vital discolored teeth: part 1. Laboratory ceramic veneer fabrication solutions. Journal of Esthetic and Restorative Dentistry, 26(4), 240-246.
91. Faus-Matoses, V., Faus-Matoses, I., Ruiz-Bell, E., \& Faus-Llácer, V. J. (2017). Severe tetracycline dental discoloration: Restoration with conventional feldspathic ceramic veneers. A clinical report. Journal of clinical and experimental dentistry, 9(11), e1379.

92. Tuzzolo Neto, H., Nascimento, W. F. D., Erly, L., Ribeiro, R. A., Barbosa, J. D. S., Zambrana, J. M., ... \& Costa, C. (2018). Laminated veneers with stratified feldspathic ceramics. Case reports in dentistry, 2018.

93. Rigolin Ferreira, F. J., Vasconcellos, A. A., Miranda, M. E., Santini, E., \& Bocabella, L. (2014). Conservative restorations combined with gingival zenith contour technique. Quintessence international, 45(10).

94. Mikeli, A., \& Walter, M. H. (2016). Impact of Bruxism on Ceramic Defects in Implant-Borne Fixed Dental Prostheses: A Retrospective Study. The International journal of prosthodontics, 29(3), 296-298.

95. de Souza Melo, G., Batistella, E. Â., BertazzoSilveira, E., Gonçalves, T. M. S. V., de Souza, B. D. M., Porporatti, A. L., ... \& Canto, G. D. L. (2018). Association of sleep bruxism with ceramic restoration failure: A systematic review and metaanalysis. The Journal of prosthetic dentistry, 119(3), 354-362.

96. de Souza Melo, G., Batistella, E. Â., BertazzoSilveira, E., Gonçalves, T. M. S. V., de Souza, B. D. M., Porporatti, A. L., ... \& Canto, G. D. L. (2018). Association of sleep bruxism with ceramic restoration failure: A systematic review and metaanalysis. The Journal of prosthetic dentistry, 119(3), 354-362.

97. Moreira, A., Freitas, F., Marques, D., \& Caramês, J. (2019). Aesthetic rehabilitation of a patient with bruxism using ceramic veneers and overlays combined with four-point monolithic zirconia crowns for occlusal stabilization: A 4-year followup. Case reports in dentistry, 2019.

Cite This Article: Rim Kallala et al. Rationalizing Indication of Ceramic Veneers: A Systematic Review. EAS J Dent Oral Med, 3(2), 51-58. 